\title{
The revised Ghent nosology for the Marfan syndrome
}

Bart L Loeys, Harry C Dietz, Alan C Braverman, et al.

J Med Genet 2010 47: 476-485

doi: 10.1136/jmg.2009.072785

Updated information and services can be found at:

http://jmg.bmj.com/content/47/7/476.full.html

\section{These include:}

References This article cites 73 articles, 16 of which can be accessed free at: http://jmg.bmj.com/content/47/7/476.full.html\#ref-list-1

Article cited in:

http://jmg.bmj.com/content/47/7/476.full.html\#related-urls

Email alerting Receive free email alerts when new articles cite this article. Sign up in the service box at the top right corner of the online article.

Notes

To order reprints of this article go to:

http://jmg.bmj.com/cgi/reprintform

To subscribe to Journal of Medical Genetics go to:

http://jmg.bmj.com/subscriptions 


\title{
The revised Ghent nosology for the Marfan syndrome
}

\author{
Bart L Loeys, ${ }^{1}$ Harry C Dietz, ${ }^{2}$ Alan C Braverman, ${ }^{3}$ Bert L Callewaert, ${ }^{1}$ \\ Julie De Backer, ${ }^{1}$ Richard B Devereux, ${ }^{4}$ Yvonne Hilhorst-Hofstee, ${ }^{5}$ \\ Guillaume Jondeau ${ }^{6}$ Laurence Faivre, ${ }^{7}$ Dianna M Milewicz, ${ }^{8}$ Reed E Pyeritz, ${ }^{9}$ \\ Paul D Sponseller, ${ }^{10}$ Paul Wordsworth, ${ }^{11}$ Anne M De Paepe ${ }^{1}$
}

${ }^{1}$ Center for Medical Genetics, Ghent University Hospital,

Ghent, Belgium

${ }^{2}$ McKusick-Nathans Institute for Genetic Medicine, Johns Hopkins University and Howard Hughes Medical Institute, Baltimore, USA

${ }^{3}$ Department of Cardiology, Washington University School of Medicine, Saint-Louis, USA

${ }^{4}$ Weill Cornell Medical College, New York, USA

${ }^{5}$ Center for Human and Clinical Genetics, Leiden University Medical Center, Leiden, the Netherlands

${ }^{6}$ Centre de Référence pour le Syndrome de Marfan et apparantés, Hopital Bichat,

Paris, France

${ }^{7}$ Center for Genetics, Children's Hospital, Dijon, France

${ }^{8}$ Department of Medical Genetics, University of Texas Medical School, Houston, USA ${ }^{9}$ Department of Medical Genetics, University of Pennsylvania, Philadelphia, USA

${ }^{10}$ Department of Orthopedics, Johns Hopkins University, Baltimore, USA

${ }^{11}$ Clinical Rheumatology, Nuffield Orthopeadic Center, Oxford, UK

\section{Correspondence to}

Professor Bart Loeys, Center for Medical Genetics, Ghent University Hospital, Building OK5, De Pintelaan 185, 9000 Gent, Belgium;

bart.loeys@ugent.be

BLL and HCD contributed equally to the manuscript

Received 26 August 2009 Revised 16 December 2009 Accepted 17 December 2009

\section{ABSTRACT}

The diagnosis of Marfan syndrome (MFS) relies on defined clinical criteria (Ghent nosology), outlined by international expert opinion to facilitate accurate recognition of this genetic aneurysm syndrome and to improve patient management and counselling. These Ghent criteria, comprising a set of major and minor manifestations in different body systems, have proven to work well since with improving molecular techniques, confirmation of the diagnosis is possible in over $95 \%$ of patients. However, concerns with the current nosology are that some of the diagnostic criteria have not been sufficiently validated, are not applicable in children or necessitate expensive and specialised investigations. The recognition of variable clinical expression and the recently extended differential diagnosis further confound accurate diagnostic decision making. Moreover, the diagnosis of MFS - whether or not established correctly — can be stigmatising, hamper career aspirations, restrict life insurance opportunities, and cause psychosocial burden. An international expert panel has established a revised Ghent nosology, which puts more weight on the cardiovascular manifestations and in which aortic root aneurysm and ectopia lentis are the cardinal clinical features. In the absence of any family history, the presence of these two manifestations is sufficient for the unequivocal diagnosis of MFS. In absence of either of these two, the presence of a bonafide FBN1 mutation or a combination of systemic manifestations is required. For the latter a new scoring system has been designed. In this revised nosology, FBN1 testing, although not mandatory, has greater weight in the diagnostic assessment. Special considerations are given to the diagnosis of MFS in children and alternative diagnoses in adults. We anticipate that these new guidelines may delay a definitive diagnosis of MFS but will decrease the risk of premature or misdiagnosis and facilitate worldwide discussion of risk and follow-up/management guidelines.

\section{INTRODUCTION}

Since Antoine-Bernard Marfan described the 5-yearold Gabrielle with skeletal manifestations of the disease that now bears his name, ${ }^{1}$ important progress has been made in the delineation of the Marfan syndrome (MFS) and recognition of associated risks. The main features of this autosomal dominant disorder include disproportionate long bone overgrowth, ectopia lentis and aortic root aneurysm. In 1955, Victor McKusick first established a classification of connective tissue disorders, which resulted in the publication of his monograph 'Heritable connective tissue disorders'. ${ }^{3}$ In 1986, an international panel of experts defined a set of clinical criteria (Berlin nosology) for the diagnosis of $\mathrm{MFS}^{4}$ with the aim of facilitating accurate communication about the condition between healthcare providers, researchers and patients. It was felt that this would improve proper patient management and effective patient counselling.

Following the identification of FBN1 (encoding fibrillin-1) as the causal gene for MFS, ${ }^{5}$ it was recognised that the Berlin criteria falsely allowed a diagnosis of MFS in individuals with a positive family history of MFS, who had only non-specific connective tissue findings themselves and who did not carry the mutation present in more typically affected family members. New diagnostic criteria were therefore put forth in 1996, referred to as the Ghent nosology. ${ }^{6}$ These Ghent criteria were more stringent than the Berlin criteria, mitigating overdiagnosis of MFS and providing better guidelines to differentiate MFS from related, 'overlapping' conditions such as the MASS phenotype (myopia, mitral valve prolapse, borderline and non-progressive aortic root dilatation, skeletal findings and striae) and mitral valve prolapse syndrome (MVPS).

Since physicians associate the diagnosis of 'Marfan syndrome', above all else, with risk for aortic aneurysm/dissection, it can be detrimental to diagnose MFS in patients without tangible evidence of such risk. Avoidable consequences associated with misdiagnosis of MFS include: restriction of career aspirations or access to insurance benefits; additional financial burden associated with frequent medical care; anxiety or situational depression; unfounded marital or reproductive decisions; loss of health benefits or psychosocial stigmatisation associated with exercise restriction, a particularly important issue during childhood. The challenge is to balance such concerns with the paramount need to maintain good health through proper counselling and application of sound anticipatory medical practices. Towards this objective, it is also important to avoid the diagnosis of MFS when clinical or molecular observations could reveal alternative (and often more severe) diagnoses that mandate specialised counselling or management protocols.

The Ghent nosology employs a set of 'major' and 'minor' manifestations in numerous tissues including the skeletal, ocular, cardiovascular, and pulmonary systems and the dura, skin and integument. ${ }^{6}$ Major manifestations include ectopia lentis, aortic root dilatation/dissection, dural ectasia or a combination of $\geq 4$ out of eight major skeletal features. The diagnosis of MFS in an index patient 
requires major involvement of at least two organ systems with minor involvement of a third organ system. In the presence of an FBN1 mutation known to cause MFS or a first degree relative who was unequivocally diagnosed based upon Ghent nosology, the presence of one major and one minor manifestation in different organ systems is sufficient to make the diagnosis.

\section{Current status of the Ghent nosology}

The Ghent criteria have found worldwide application in helping physicians to diagnose MFS appropriately. New molecular techniques allow the detection of FBN1 mutations in up to $97 \%$ of Marfan patients who fulfil the Ghent criteria. ${ }^{7}$ This suggests that the current Ghent criteria have excellent specificity to identify patients with FBN1 mutations. Consideration of sensitivity is highly complex due to varying definitions of the 'target' population and competing clinical priorities. For example, the current criteria have been criticised for taking insufficient account of the age dependent nature of some clinical manifestations (making the diagnosis in children more difficult) ${ }^{9}$ and for including some rather non-specific physical manifestations or poorly validated diagnostic thresholds. Although the assignment of major and minor criteria within the Ghent nosology has contributed to its utility, several of those criteria are not intuitive when considered from the perspective of the differential diagnosis or patient management. Consideration of the diagnosis of familial ectopia lentis is particularly illustrative of the prevailing issues. This diagnostic category has been widely applied for individuals and families that show lens dislocation and skeletal features of MFS but do not show aortic enlargement or dissection. FBN1 mutations are seen in familial ectopia lentis and are not easily distinguished from those causing MFS on the basis of character or location within the gene-suggesting either occult phenotype-genotype correlations or the influence of modifiers.

The Ghent nosology clearly attempted to accommodate the fact that some people with ectopia lentis, skeletal findings and even FBN1 mutation have less cardiovascular risk (ie, risk to the aortic root) than seen in classic MFS, by allowing the diagnosis of familial ectopia lentis in the absence of a second major Marfan manifestation. However, inadequate data were available to evaluate the critical issue of whether cardiovascular risk could be predicted by the presence of non-cardiac features, such as dural ectasia or major versus minor skeletal involvement. At the other extreme, is it justified not to diagnose MFS in someone with typical lens dislocation and aortic root enlargement simply because they lack minor skeletal or skin findings? To address some of these issues, an international panel (see acknowledgement) of experts in the diagnosis and management of MFS was convened in Brussels, Belgium by the National Marfan Foundation (USA) and charged with considering modifications to the Ghent criteria. Other factors under consideration included the specialised nature, availability and cost of diagnostic tests for selected manifestations (eg, dural ectasia), the need to define certain diagnostic categories better (eg, familial ectopia lentis, MASS phenotype ${ }^{10}$ and MVPS), to define features that should trigger alternative diagnoses and a desire to complement diagnostic criteria with follow-up, and management guidelines for various patient groups including children who do not yet fulfil the diagnostic criteria but may do so in the future.

\section{Proposal for new nosology}

This proposal for a revised nosology (box 1) was based on critical review of clinical characteristics in large published patient
Box 1 Revised Ghent criteria for diagnosis of Marfan syndrome and related conditions

In the absence of family history:

(1) Ao $(Z \geq 2)$ AND EL=MFS*

(2) Ao $(Z \geq 2)$ AND $F B N 1=$ MFS

(3) Ao $(Z \geq 2)$ AND Syst $(\geq 7 \mathrm{pts})=\mathrm{MFS}^{*}$

(4) EL AND FBN1 with known $\mathrm{A} 0=\mathrm{MFS}$

EL with or without Syst AND with an FBN1 not known with Ao or no $F B N 1=$ ELS

Ao $(Z<2)$ AND Syst ( $\geq 5$ with at least one skeletal feature) without $E L=M A S S$

MVP AND Ao $(Z<2)$ AND Syst $(<5)$ without EL=MVPS

In the presence of family history:

(5) EL AND FH of MFS (as defined above)=MFS

(6) Syst ( $\geq 7$ pts) AND FH of MFS (as defined above)=MFS*

(7) Ao ( $Z \geq 2$ above 20 years old, $\geq 3$ below 20 years) $+F H$ of MFS (as defined above) $=$ MFS ${ }^{*}$

* Caveat: without discriminating features of SGS, LDS or vEDS (as defined in table 1) AND after TGFBR1/2, collagen biochemistry, COL3A1 testing if indicated. Other conditions/genes will emerge with time.

Ao, aortic diameter at the sinuses of Valsalva above indicated Z-score or aortic root dissection; EL, ectopia lentis; ELS, ectopia lentis syndrome; $F B N 1$, fibrillin-1 mutation (as defined in box 3); FBN1 not known with Ao, FBN1 mutation that has not previously been associated aortic root aneurysm/dissection; FBN1 with known Ao, FBN1 mutation that has been identified in an individual with aortic aneurysm; MASS, myopia, mitral valve prolapse, borderline $(Z<2)$ aortic root dilatation, striae, skeletal findings phenotype; MFS, Marfan syndrome; MVPS, mitral valve prolapse syndrome; Syst, systemic score (see box 2); and Z, Z-score.

cohorts, $^{7} 81112$ and expert opinions of the panel members with extensive experience in applying the current criteria, the differential diagnosis of MFS, and the strengths and limitations of molecular genetic testing. Several guiding principles were followed: maximal use of evidence based decision making; attention to practical (patient centric) implications; a focus on features and criteria that distinguish MFS from other disorders; and definition of purposeful thresholds for diagnosis. As a result, five major changes in the diagnostic guidelines are proposed.

First, more weight is given to two cardinal features of MFS, aortic root aneurysm/dissection and ectopia lentis. In the absence of findings that are not expected in MFS, the combination of ectopia lentis and aortic root enlargement/dissection should be sufficient to make the diagnosis. All other cardiovascular and ocular manifestations of MFS and findings in other organ systems, such as the skeleton, dura, skin and lungs, contribute to a 'systemic score' (box 2) that guides diagnosis when aortic disease is present but ectopia lentis is not.

Second, a more prominent role is assigned to molecular genetic testing of FBN1 and other relevant genes (eg, TGFBR1 and 2), as well as other genes indicated in table 1. In practice, this does not make FBN1 testing a formal requirement (which imposes financial burden in some countries, and does not yet have $100 \%$ sensitivity and specificity), but allows its appropriate use when available. 


\section{Box 2 Scoring of systemic features}

- Wrist AND thumb sign - 3 (wrist OR thumb sign - 1)

- Pectus carinatum deformity -2 (pectus excavatum or chest asymmetry -1$)$

- Hindfoot deformity - 2 (plain pes planus - 1)

- Pneumothorax -2

- Dural ectasia - 2

- Protrusio acetabuli - 2

- Reduced US/LS AND increased arm/height AND no severe scoliosis - 1

- Scoliosis or thoracolumbar kyphosis - 1

- Reduced elbow extension - 1

- Facial features $(3 / 5)-1$ (dolichocephaly, enophthalmos, downslanting palpebral fissures, malar hypoplasia, retrognathia)

- Skin striae -1

- Myopia > 3 diopters - 1

- Mitral valve prolapse (all types) -1

Maximum total: 20 points; score $\geq 7$ indicates systemic

involvement; US/LS, upper segment/lower segment ratio.

Third, some of the less specific manifestations of MFS were either removed or made less influential in the diagnostic evaluation of patients. This avoids the use of obligate thresholds that lack clear validation or general availability.

Fourth, the new criteria formalise the concept that additional diagnostic considerations and testing are required if a patient has sufficient findings to satisfy the criteria for MFS but also shows unexpected findings, particularly if they segregate with disease in the family or if they are suggestive of a specific alternative diagnosis. Particular emphasis is placed on Sphrintzen-Goldberg syndrome (SGS), Loeys-Dietz syndrome (LDS), and the vascular form of Ehlers-Danlos syndrome (vEDS). SGS and LDS have substantial overlap with MFS, including the potential for similar involvement of the skeleton, aortic root, skin and dura (table 1). Occasionally, vEDS shows overlap in the vascular system, dura, skin and skeleton. It is essential to consider discriminating features (table 1 ) because each of these conditions has a unique risk profile and management protocol.

Finally, this nosology should help to allay concerns regarding delayed or ambiguous diagnoses by providing context specific recommendations for patient counselling and follow-up.
In the revised nosology, new diagnostic criteria have been defined for a sporadic patient and for an index patient with a positive family history (box 1). In the absence of a conclusive family history of MFS, the diagnosis can be established in four distinct scenarios:

1. The presence of aortic root dilatation (Z-score $\geq 2$ when standardised to age and body size) or dissection ${ }^{13}$ and ectopia lentis allows the unequivocal diagnosis of MFS, irrespective of the presence or absence of systemic features except where these are indicative of SGS, LDS or vEDS (table 1).

2. The presence of aortic root dilatation $(Z \geq 2)$ or dissection and the identification of a bona fide FBN1 mutation (box 3) is sufficient to establish the diagnosis even when ectopia lentis is absent. An overview of criteria that enhance confidence in the pathogenetic potential for MFS of particular FBN1 mutations is provided in box 3 . These include missense mutations that substitute or create cysteine residues, alter one of the conserved residues important for calcium binding in epidermal growth factor-like (EGF) domains, create a premature termination codon (nonsense mutations), delete or insert coding sequence, or disrupt the consensus sequence for pre-mRNA splicing. Evidence for pathogenicity of other types of missense mutations would include its absence in at least 400 ethnically matched control chromosomes and co-segregation with disease in the family, or de novo occurrence in a sporadic case (with confirmation of paternity). Definitive evidence of linkage to a predisposing FBN1 haplotype can substitute for an FBN1 mutation for diagnostic purposes, but this linkage analysis requires at least six informative meioses in the patient's family to confirm the MFS associated FBN1 allele. The absence of a mutation in the $F B N 1$ gene despite complete screening is possible in MFS.

3. Where aortic root dilatation $(Z \geq 2)$ or dissection is present but ectopia lentis is absent and the FBN1 status is either unknown or negative, an MFS diagnosis is confirmed by the presence of sufficient systemic findings ( $\geq 7$ points, according to a new scoring system) (box 2). However, features suggestive of SGS, LDS or vEDS must be excluded and appropriate alternative genetic testing (TGFBR $1 / 2$, collagen biochemistry, COL3A1, and other relevant genetic testing when indicated and available upon the discovery of other genes) should be performed.

4. In the presence of ectopia lentis but absence of aortic root dilatation/dissection, the identification of an FBN1 mutation previously associated with aortic disease is required before

Table 1 Features of differential diagnosis

\begin{tabular}{|c|c|c|}
\hline Differential diagnosis & Gene & Discriminating features \\
\hline Loeys-Dietz syndrome (LDS) & TGFBR1/2 & $\begin{array}{l}\text { Bifid uvula/cleft palate, arterial tortuosity, hypertelorism, diffuse } \\
\text { aortic and arterial aneurysms, craniosynostosis, clubfoot, } \\
\text { cervical spine instability, thin and velvety skin, easy bruising }\end{array}$ \\
\hline Congenital contractural arachnodactyly (CCA) & FBN2 & Crumpled ears, contractures \\
\hline Weill-Marchesani syndrome (WMS) & FBN1 and ADAMTS10 & Microspherophakia, brachydactyly, joint stiffness \\
\hline Ectopia lentis syndrome (ELS) & $\begin{array}{l}\text { FBN1 } \\
\text { LTBP2 } \\
\text { ADAMTSL4 }\end{array}$ & Lack of aortic root dilatation \\
\hline Homocystinuria & CBS & Thrombosis, mental retardation \\
\hline $\begin{array}{l}\text { Familial thoracic aortic aneurysm syndrome (FTAA) } \\
\text { FTAA with bicupid aortic valve (BAV) }\end{array}$ & TGFBR1/2, ACTA2 & $\begin{array}{l}\text { Lack of Marfanoid skeletal features, levido reticularis, iris } \\
\text { flocculi }\end{array}$ \\
\hline FTAA with patent ductus arteriosus (PDA) & MYH11 & \\
\hline Arterial tortuosity syndrome (ATS) & SLC2A10 & $\begin{array}{l}\text { Generalised arterial tortuosity, arterial stenosis, facial } \\
\text { dysmorphism }\end{array}$ \\
\hline
\end{tabular}




\section{Box 3 Criteria for causal FBN1 mutation}

- Mutation previously shown to segregate in Marfan family

- De novo (with proven paternity and absence of disease in parents) mutation (one of the five following categories)

- Nonsense mutation

- Inframe and out of frame deletion/insertion

- Splice site mutations affecting canonical splice sequence or shown to alter splicing on mRNA/cDNA level

- Missense affecting/creating cysteine residues

- Missense affecting conserved residues of the EGF consensus sequence $((\mathrm{D} / \mathrm{N}) \mathrm{X}(\mathrm{D} / \mathrm{N})(\mathrm{E} / \mathrm{Q}) \mathrm{Xm}(\mathrm{D} / \mathrm{N}) \mathrm{Xn}(\mathrm{Y} / \mathrm{F})$ with $\mathrm{m}$ and $n$ representing variable number of residues; $D$ aspartic acid, $N$ asparagine, $\mathrm{E}$ glutamic acid, 0 glutamine, $\mathrm{Y}$ tyrosine, $\mathrm{F}$ phenylalanine)

- Other missense mutations: segregation in family if possible + absence in 400 ethnically matched control chromosomes, if no family history absence in 400 ethnically matched control chromosomes

- Linkage of haplotype for $\mathrm{n} \geq 6$ meioses to the FBN1 locus

making the diagnosis of MFS. If the FBN1 mutation is not unequivocally associated with cardiovascular disease in either a related or unrelated proband, the patient should be classified as 'ectopia lentis syndrome' (see differential diagnosis).

In an individual with a positive family history of MFS (where a family member has been independently diagnosed using the above criteria), the diagnosis can be established in the presence of ectopia lentis, or a systemic score $\geq 7$ points or aortic root dilatation with $Z \geq 2$ in adults ( $\geq 20$ years old) or $Z \geq 3$ in individuals $<20$ years old.

Special consideration should be given to young individuals $(<20$ years old). In sporadic cases, these children may not fit in one of the four proposed scenarios. If insufficient systemic features $(<7)$ and/or borderline aortic root measurements $(Z<3)$ are present (without FBN1 mutation), we suggest to use the term 'non-specific connective tissue disorder' until follow-up echocardiographic evaluation shows aortic root dilation $(Z \geq 3)$. If an $F B N 1$ mutation is identified in sporadic or familial cases but aortic root measurements are still below $Z=3$, we propose to use the term 'potential MFS' until the aorta reaches threshold. Neonatal MFS is not considered as a separate category, but rather represents the severe end of the MFS spectrum.

In adults ( $>20$ years), we define three main categories of alternative diagnoses: ectopia lentis syndrome (ELS), MASS phenotype (myopia, mitral valve prolapse, borderline $(Z<2)$ aortic root enlargement, skin and skeletal findings), and mitral valve prolapse syndrome (MVPS) (see differential diagnosis).

Finally, we recognise that some patients will remain difficult to classify due to overlap of phenotypes from different entities, the evolving nature of these connective tissue diseases, absence of mutation after screening of the appropriate genes, or divergence between the phenotype and the genotype. However, these patients should be uncommon and will hopefully benefit from better definition of still unrecognised phenotypes in the future.

\section{ORGAN SYSTEM SPECIFIC CONSIDERATIONS Cardiovascular criteria}

A key diagnostic criterion in the new nosology is aortic root aneurysm or dissection. Aortic root aneurysm is defined as enlargement of the aortic root at the level of the sinuses of
Valsalva. Aortic root measurements should be done parallel to the plane of the aortic valve and perpendicular to the axis of blood flow. The largest correctly measured root diameter obtained from at least three transthoracic images should be corrected for age and body size and interpreted as a Z-score. There are varying practices regarding whether root measurements should be done in systole or diastole and whether the thickness of one aortic wall should be included (ie, the leading edge to leading edge method). The method employed must match that used to generate the normative data for Z-scores to be valid. For echocardiographic measurements made from inner wall to inner wall during systole in individuals $\leq 25$ years, a convenient Z-score calculator can be found at http://www. marfan.org. For echocardiographic measurements made from leading edge to leading edge in diastole in all age groups, reference graphs and Z-score equations are available ${ }^{13}$. If transthoracic echocardiographic evaluations do not allow precise visualisation of the proximal aorta, transoesophageal echocardiography or CT or MRI imaging should be applied, with special attention to using double-oblique images to obtain correct diameter measurements and use of the same nomograms. ${ }^{14}$

Mitral valve prolapse is also a common finding in MFS and is included as a feature in the systemic score. Mitral valve prolapse should be defined by echocardiography as protrusion of one or both of the mitral valve leaflets across the plane of the mitral annulus during systole. This is best detected in parasternal long axis or apical long axis three-chamber or two-chamber views. There are no special criteria for diagnosing MVP in MFS and standard practices should be applied. ${ }^{15}$

Pulmonary artery (PA) dilation (eg, main PA diameter $>23 \mathrm{~mm}$ in adults) ${ }^{16}$ is often seen in MFS, but it is not specific to this diagnosis. In addition, complications of pulmonary artery disease occur rarely. PA dilation was not therefore included in the systemic score because further research is needed regarding thresholds and the diagnostic utility of this finding.

Patients with MFS can develop aortic enlargement or dissection at segments distant from the aortic root. The frequency of this finding (particularly at the proximal descending thoracic aorta and in the abdomen) appears to be increasing with the prolonged survival due to improved management of disease at the aortic root. While descending aortic aneurysm or dissection in the absence of aortic root enlargement can occur in Marfan syndrome, ${ }^{1718}$ this is rare and given the low specificity of this finding for MFS, this finding is not included in the diagnostic criteria. Intermittent imaging of the descending thoracic aorta is indicated in adult patients where there is a clinical suspicion of Marfan syndrome in the absence of aortic root enlargement. Widespread vascular disease is more common with other conditions in the differential diagnosis, such as vascular EDS and LDS. For example, systemic vascular imaging (head to pelvis) is recommended if there is a suspicion of LDS because of the high frequency of tortuosity, aneurysms and dissections throughout the vascular tree.

\section{Ocular criteria}

The most prominent ocular features of MFS are myopia and ectopia lentis. The diagnosis of ectopia lentis is based on slitlamp examination after maximal dilatation of the pupil. Ectopia lentis reflects failure of supporting structures called ciliary zonules. Dislocation of the lens in MFS is most typically upward and temporal, but deviation in any direction may occur. If lens subluxation is deemed equivocal or minimal, manifesting only as a scalloped or ruffled lens margin at extremes of gaze, the eye exam should be repeated later before a definitive diagnosis of ectopia lentis can be made (such findings can occur outside the 
context of MFS, eg, in individuals with high myopia). Increased globe length and corneal flattening are seen in MFS, but they have unclear specificity and are not routinely measured by ophthalmologists. Given that myopia is very common in MFS, is routinely monitored, and tends to show early onset, high severity and rapid progression, myopia of $>3$ diopters contributes to the systemic score for diagnosis. However, since myopia is quite a common finding in the general population we have only attributed one point to it in the systemic score.

\section{Systemic criteria}

Clinical manifestations of MFS in other organ systems were critically evaluated for their specificity and diagnostic utility based on expert opinion and the available literature. Several of the 'minor' criteria from the old Ghent nosology were eliminated, but the most selective systemic features were included in the 'systemic score'.

Three points are assigned to the combination of wrist and thumb signs. The thumb sign is positive when the entire distal phalanx of the adducted thumb extends beyond the ulnar border of the palm with or without the assistance of the patient or examiner to achieve maximal adduction. The wrist sign is positive when the tip of the thumb covers the entire fingernail of the fifth finger when wrapped around the contralateral wrist. If either of the two signs is absent, only one point is assigned.

Two points were assigned to each of five other specific systemic manifestations including anterior chest deformity, hindfoot deformity, spontaneous pneumothorax, dural ectasia and acetabular protrusion. Pectus carinatum is believed to be more specific for MFS than pectus excavatum and is assigned two points. Subjective qualifiers in the original Ghent criteria such as 'requiring surgery' have been eliminated, but the examiner should be confident that a positive finding (pectus excavatum or chest wall asymmetry) extends beyond normal variation of chest contour in the general population before assigning one point. Hindfoot valgus ${ }^{19}$ (two points) in combination with forefoot abduction and lowering of the midfoot (previously referred to as medial rotation of the medial malleolus) should be evaluated from anterior and posterior view. The examiner should distinguish this from the more common 'flat foot' (one point) without significant hindfoot valgus. As in the past, any spontaneously occurring pneumothorax remains a diagnostic feature. For the detection of lumbosacral dural ectasia, no preferred method (CT or MRI) or uniformly accepted cut-offs have emerged from the literature ${ }^{20-23}$ and local standards should apply. Dural ectasia is a sensitive but not a specific sign of MFS and, as such, is no longer considered on equal footing with lens dislocation or aortic root enlargement. It is commonly seen in LDS and has been described in mutation proven vEDS. Finally, an additional technical exam for detection of acetabular protrusion ${ }^{24}$ can be helpful but is not mandatory: classical x-ray, CT or MRI can be used. On an x-ray anterior-posterior pelvis angle, the medial protrusion of the acetabulum at least $3 \mathrm{~mm}$ beyond the ilio-ischial (Kohler) line is diagnostic. Criteria on CT or MRI are not precisely defined but involve loss of the normal oval shape of the pelvic inlet at the level of the acetabulum.

One point is assigned to eight other manifestations, one cardiovascular (mitral valve prolapse), one ocular (myopia, $\geq 3$ diopters) and six features from other organ systems. These are considered less specific features for MFS and can be observed in other connective tissue disorders or as normal variation in the general population. ${ }^{18}$

The combined presence of reduced upper segment to lower segment (US/LS) ratio (for white adults $<0.85 ;<0.78$ in black adults; no data have been assessed in Asians) and increased arm span to height ratio (for adults $>1.05$ ) in the absence of significant scoliosis contributes one point to the systemic score. In Asians the incidence of an enlarged arm span to height ratio in Marfan patients was noted to be lower ${ }^{25}$ and prior studies of Asian (and also Afro-Caribbean) populations demonstrated different distributions of arm span and height, so one should consider these ethnic differences when using cut-off values. ${ }^{26}$ For the US/LS ratio in children, abnormal ratios are US/LS $<1$ (for age $0-5$ years), US/LS $<0.95$ (for $6-7$ years), US/LS $<0.9$ (8-9 years old) and $<0.85$ (above age 10 years). The lower segment is defined as the distance from the top of the symphysis pubis to the floor in the standing position, and the upper segment is the height minus the lower segment. Importantly, neither of these ratios provides an accurate measurement of bone overgrowth in the presence of severe scoliosis or kyphosis. Scoliosis ${ }^{27}$ can be diagnosed either clinically if, upon bending forward, a vertical difference of least $1.5 \mathrm{~cm}$ between the ribs of the left and right hemithorax is observed or if a Cobb's angle (angle between a line drawn along the superior end plate of the superior end vertebra and a second line drawn along the inferior end plate of the inferior end vertebra of the scoliosis measured on anterior-posterior view of the spine) of at least $20^{\circ}$ is seen on radiographs. In the absence of scoliosis, one point can be contributed by the presence of an exaggerated thoracolumbar kyphosis. Elbow extension is considered reduced if the angle between the upper and lower arm measures $170^{\circ}$ or less upon full extension. One point can be assigned based upon facial characteristics if the patient shows at least three of the five typical facial characteristics including dolichocephaly, downward slanting palpebral fissures, enophthalmos, retrognathia and malar hypoplasia. Striae atrophicae are considered significant as a diagnostic feature if they are not associated with pronounced weight changes (or pregnancy) and if they have an uncommon location such as the mid back, lumbar region, the upper arm, axillary region or thigh.

The following criteria were removed from the current nosology because of lack of perceived specificity: joint hypermobility, highly arched palate, and recurrent or incisional herniae. $^{18}$

\section{Differential diagnosis}

Several conditions have been recognised which present overlapping clinical manifestations with MFS in the cardiovascular, ocular or skeletal systems. These include conditions with aortic aneurysms (LDS, bicuspid aortic valve, familial thoracic aortic aneurysm, vEDS, arterial tortuosity syndrome), ectopia lentis (ectopia lentis syndrome, Weil-Marchesani syndrome, homocystinuria, Stickler syndrome) or systemic manifestations of MFS (Shprintzen-Goldberg syndrome, congenital contractural arachnodactyly, LDS, MASS phenotype and MVPS (table 1).

\section{Conditions with cardiovascular features of MFS}

Historically the terms MASS phenotype and MVPS have been used but several issues about the use of these terms have arisen. First, the definition of the MASS phenotype is not unequivocally applicable as it required at least two, but preferably three, of the following manifestations: myopia, mitral valve prolapse, borderline aortic root enlargement, skin and minor skeletal features (insufficient to fulfil the major skeletal criterion of the original Ghent nosology). ${ }^{6}$ This definition indirectly also assumes a non-progressive nature of the aortic root dilatation, but it is currently unknown to what proportion of patients this applies. Third, FBN1 mutations have been found occasionally in 
MASS phenotype patients, ${ }^{18}{ }^{28}$ but the precise risk for the development of aortic aneurysm and progression for these patients is poorly studied. Analogous to the ectopia lentis syndrome, the spirit of the definition of MASS phenotype aims to avoid the diagnosis of MFS without documented risk for aortic root aneurysm development. The diagnosis of MASS is made in individuals with an aortic root size below $Z=2$, at least one skeletal feature and a systemic score $\geq 5$. The presence of ectopia lentis precludes this diagnosis. If an FBN1 mutation is identified in a MASS patient, this patient has the potential to evolve into MFS, but it is currently unknown how often and which factors predict this transition over time.

Alternatively, when mitral valve prolapse is present in association with limited systemic features (score $<5$ ), we suggest use of the term mitral valve prolapse syndrome (MVPS). MVPS is a common condition usually inherited in autosomal dominant mode ${ }^{29}$ with several candidate gene loci, ${ }^{30}$ but with evidence for rare X-linked inheritance ${ }^{31}$ which affects $\sim 1.5 \%$ of the population. In addition to prolapse of the mitral leaflets, MVPS commonly includes pectus excavatum, scoliosis and mild arachnodactyly. ${ }^{32}$ However, aortic enlargement and ectopia lentis preclude this diagnosis.

Loeys-Dietz syndrome (LDS) is an autosomal dominant aortic aneurysm syndrome characterised by the triad of hypertelorism, bifid uvula/cleft palate, and/or arterial tortuosity with ascending aortic aneurysm/dissection. It is caused by heterozygous mutations in the genes encoding the type 1 or 2 subunit of the transforming growth factor- $\beta$ receptor (TGFBR1 or TGFBR2). ${ }^{33}$ Other more variable clinical features that distinguish LDS from MFS include craniosynostosis, Chiari malformation, clubfoot deformity, congenital heart disease, cervical spine instability, easy bruising, dystrophic scarring, translucent skin and, most importantly, a high risk of aneurysm and dissection throughout the arterial tree. Patients with LDS are not typically inappropriately tall and do not exhibit disproportionally long extremities, although arachnodactyly is observed. Some patients with TGFBR $1 / 2$ mutations lack overt craniofacial features despite an equal or greater severity of vascular or systemic findings. Importantly, the natural history of patients with LDS tends to be more aggressive than those with MFS or vEDS. In LDS, aortic dissections often occur at a younger age or at smaller aortic dimensions $(<40 \mathrm{~mm})$ compared to MFS, and the incidence of pregnancy related complications is particularly high. ${ }^{34}$ As with FBN1 mutations, the phenotype associated with $T G F B R 1 / 2$ mutations can be variable, even within families, and can be associated with skeletal features of MFS leading to overlapping phenotypes in the old Ghent nosology. ${ }^{35-37}$ In order to avoid persistent ambiguity even under the proposed criteria, molecular testing should be strongly considered because it influences the clinical management. ${ }^{34}$ It has been proposed that patients with TGFBR $1 / 2$ mutations who lack outward discriminating features of LDS should be designated LDS2, highlighting the potential for more aggressive vascular disease than seen in Marfan syndrome (MIM 190181 and 190182).

With a population prevalence of up to $1 \%,{ }^{38} 39$ bicuspid aortic valve (BAV) is the most common congenital cardiac malformation. A subset of individuals with BAV present with ascending aortic aneurysm; however, such patients usually lack ocular or other systemic findings that contribute strongly to MFS diagnosis. Skeletal findings such as pectus deformity and scoliosis can be observed in these families. BAV and aortic aneurysm can occur together in some family members but independently in others, indicating that they can be variably penetrant consequences of a common underlying genetic defect. ${ }^{40} 41$ Unlike
MFS, this condition commonly shows maximal or exclusive dilatation in the ascending aorta above the sinotubular junction. ${ }^{42}$ Mutations have been identified in the NOTCH1 and KCNJ2 genes, but these account for only a small fraction of BAV patients, who may have prominent valve calcification or associated forms of congenital heart disease. Linkage analysis reveals genetic heterogeneity with putative loci on chromosomes 18q, $5 \mathrm{q}$ and $13 \mathrm{q} .{ }^{43}$

Familial thoracic aortic aneurysm and dissection syndrome (FTAAD) is a clinically and genetically heterogeneous group of disorders where thoracic aortic disease predominates. The age of onset and rate of progression of aortic dilatation is highly variable and conditions that include variable or subtle systemic manifestations of a connective tissue disorder have been included in this designation. It is anticipated that future stratification of patients by genetic aetiology will help to refine phenotypic descriptions and inform patient counselling and management. To date, there are five genes and two additional loci $^{44} 45$ associated with FTAAD. Mutations have been identified in FBN1, TGFBR1/2, MYH11, and ACTA2, the latter two encoding components in the smooth muscle cell contractile apparatus. Mutations in $M Y H 11$ associate aortic root aneurysms with patent ductus arteriosus (PDA). ${ }^{46}$ Mutations in ACTA2, accounting for up to $16 \%$ of FTAAD, associate aortic aneurysm with other variable features including iris flocculi, livedo reticularis, cerebral aneurysm, BAV and $\mathrm{PDA}^{47}$ In addition to thoracic aortic aneurysms and dissections, patients with ACTA2 mutations can present with vascular disease in the cerebrovascular system (premature ischaemic strokes, Moyamoya disease and cerebral aneurysms) or premature coronary artery disease. ${ }^{48}$

The vascular type of EDS (previously EDS IV), is caused by mutations in COL3A1, the gene encoding type III collagen; it is characterised by vascular and tissue fragility. Cardinal features distinguishing vEDS from MFS include translucent skin, easy bruising, dystrophic scarring and a tendency for intestinal or uterine rupture. Typically, dissection or rupture occurs in medium sized arteries in vEDS, although aortic involvement is sometimes observed. There is no particular predisposition at the aortic root. About half of the aneurysms/dissections occur in thoracic or abdominal branch arteries; arteries of the head, neck and limbs are less frequently involved. ${ }^{49}$

Three other rare types of EDS have been associated with vascular problems. The kyphoscoliotic type (previously type VI EDS) is characterised by kyphoscoliosis, joint laxity, and muscle hypotonia. This autosomal recessive condition is caused by defects in the enzymatic activity of lysyl hydroxylase, encoded by the PLOD1 gene. Aortic dilation/dissection and rupture of medium sized arteries have been observed. ${ }^{50}$ Patients with the so-called 'cardiac valvular subtype of EDS', which associates severe cardiac valvular problems and features of the classic type of EDS (atrophic scars, skin hyperelasticiy and joint hypermobility), were found to have a complete deficiency of the proa2chain of type I collagen (COL1A2). ${ }^{51}$ Most recently, patients with arginine to cysteine substitutions in the proa1-chain of type I collagen (COL1A1) displayed classic EDS but evolved to a vascular EDS-like phenotype later in life, with increased risk for spontaneous arterial rupture, most prominently affecting the femoral and iliac arteries. ${ }^{52}$

Arterial tortuosity syndrome (ATS) is a rare autosomal recessive connective tissue disorder, characterised by severe tortuosity, stenosis, and aneurysms of the aorta and medium sized arteries. ${ }^{53}$ Skeletal and skin involvement is common. The underlying genetic defect is homozygosity or compound heterozygosity for loss-of-function mutations in SLC2A10, the 
gene encoding the facilitative glucose transporter GLUT10. ${ }^{54}$ The condition is lethal in infancy in a subset of patients, but some survive into adulthood and seem to do well. ${ }^{55}$

\section{Conditions with ectopia lentis}

Patients with familial ectopia lentis typically have some skeletal features of MFS and an FBN1 mutation. While lack of aortic disease is a defining feature of this condition, it may be difficult to distinguish from emerging MFS in the absence of other affected family members or at a young age. Even within extended pedigrees with familial ectopia lentis, later onset aortic aneurysm may be observed. In order to better highlight the systemic nature of this condition and to emphasise the need for assessment of features outside the ocular system, we propose the designation ectopia lentis syndrome (ELS). The presence of a personal or family history of aortic aneurysm, or the identification of an FBN1 mutation previously associated with aortic aneurysm, would be sufficient to transition the diagnosis to MFS, independently of the number or distribution of systemic features. To ensure that adequate vigilance of other organ systems is maintained, the diagnosis of ELS cannot be formally invoked before the age of 20 years. The disorder is genetically heterogeneous, with autosomal dominant inheritance caused by FBN1 mutations ${ }^{56}$ and recessive forms caused by LTBP2 and ADAMTSL4 mutations. ${ }^{57} 58$ Importantly, in ELS patients with FBN1 mutations, cardiovascular follow-up by imaging should be maintained throughout life.

Ectopia lentis can be present as a component of other rare conditions. Ectopia lentis et pupillae is an autosomal recessive condition in which remnants of the pupillary membrane are present. However, it is not associated with cardiovascular or skeletal features of MFS.

In Weill-Marchesani syndrome (WMS), the lens dislocation is typically associated with microspherophakia (small, rounded and thickened crystalline lens) and a shallow anterior eye chamber. WMS patients are short with brachydactyly and joint stiffness. Both autosomal dominant and recessive forms of WMS have been described and are caused by FBN1 mutations ${ }^{59} 60$ or mutations in the ADAMTS10 gene, ${ }^{61}$ respectively. Homocystinuria is often easily differentiated from MFS by the presence of mental retardation and thrombosis, and can be excluded by urine amino acid analysis in the absence of pyridoxine supplementation. In homocystinuria, the lens usually dislocates downward due to complete loss of support by ciliary zonules. In Stickler syndrome, patients can present with a Marfanoid habitus. Typical ocular signs include vitreal degeneration, retinal detachment, myopia and open angle glaucoma. Early cataracts are common, but lens subluxation is not. Other potential discriminating features from MFS include cleft palate, hearing loss and epiphysial changes of the bones.

\section{Conditions with overlapping systemic features}

Shprintzen-Goldberg syndrome (SGS) is a rare craniosynostosis syndrome characterised by some of the systemic features found in MFS (pectus abnormalities, scoliosis, arachnodactyly), craniofacial dysmorphism (exophthalmos, hypertelorism, downslanting palpebral fissures, maxillary and mandibular hypoplasia, high arched palate and low set ears) and developmental delay. So far, only two SGS patients have shown an FBN1 mutation. ${ }^{62}{ }^{63}$ Another patient reported by Kosaki et al ${ }^{63}$ as SGS was felt to have LDS based on arterial tortuosity and the presence of a bifid uvula. ${ }^{64}$ Other important distinguishing features between SGS and either LDS or MFS are the high incidence of cognitive impairment and the low frequency of vascular disease in the former.
Congenital contractural arachnodactyly (CCA) is an autosomal dominant disorder characterised by a Marfan-like body habitus and arachnodactyly. ${ }^{65}$ Most affected individuals have 'crumpled' ears that present as a folded upper helix, and contractures of major joints (knees and ankles) at birth. The proximal interphalangeal joints of the fingers and toes have flexion contractures (camptodactyly). Kyphosis/scoliosis is present in about half of affected individuals. Mild enlargement of the sinuses of Valsalva has been reported, but there is no evidence that the aortic dilatation progresses to dissection or rupture. $^{66} \mathrm{CCA}$ is caused by mutations in FBN2, the gene encoding the extracellular matrix protein fibrillin-2. ${ }^{67}$

\section{MANAGEMENT}

\section{Management guidelines for MFS patients}

Aortic root dilatation in MFS is usually progressive. Therefore absence of aortic root enlargement on initial clinical examination does not necessarily exclude the diagnosis, even in adulthood.

All individuals who meet the criteria for MFS should initially have at least yearly echocardiograms. More frequent imaging should be performed if the aortic diameter is approaching a surgical threshold ( $\geq 4.5 \mathrm{~cm}$ in adults; less well defined in children) or shows rapid change $(\geq 0.5 \mathrm{~cm} /$ year $)$ or with concerns regarding heart or valve function. Individuals under age 20 with systemic findings suggestive of MFS but no cardiovascular involvement should have annual echocardiograms due to the potential for rapid evolution of the phenotype. Adults with repeatedly normal aortic root measurements can be seen at intervals of $2-3$ years.

Although several alternative medical treatments have been proposed (angiotensin converting enzyme (ACE) inhibitors, calcium channel antagonists), the standard of care in most centres for the prevention of aortic complications in MFS remains $\beta$-blockade. ${ }^{68}$ More data are required before ACE inhibitor therapy can be considered standard treatment. ${ }^{69} \beta$ blockade should be considered in all patients with MFS, including children and those with aortic root diameters $<4 \mathrm{~cm}$, unless contraindicated. The $\beta$-blocker should be titrated to effect, aimed at a heart rate after submaximal exercise (eg, running up and down two flights of stairs) $<100$ beats/min in individuals over 5 years of age. Angiotensin receptor blockers (ARBs) have shown the ability to prevent aortic enlargement in a mouse model of Marfan syndrome, ${ }^{70}$ and encouraging results were observed in a pilot experience in children with severe MFS. ${ }^{71}$ Several multicentre trials of losartan versus or on top of atenolol in MFS are currently underway. ${ }^{72}$ If $\beta$-blockers are contraindicated or not tolerated, other classes of antihypertensive agents can be used, but there is not definitive evidence that they will afford protection in people with MFS.

Management of acute dissection of the ascending aorta (type A dissection) is emergency surgery. Consideration of prophylactic surgery is recommended when the diameter at the sinuses of Valsalva approaches $5.0 \mathrm{~cm}$. Other factors that inform the timing of surgery include a family history of early dissection, the rate of aortic root growth, the severity of aortic valve regurgitation, associated mitral valve disease, ventricular dysfunction, pregnancy planning in women, and the desire for a valve sparing operation.

Type $\mathrm{B}$ dissection (originating in the thoracic descending aorta) accounts for about $10 \%$ of all dissections in MFS. Possible indications for surgery include intractable pain, limb or organ ischaemia, an aortic diameter exceeding $5.5 \mathrm{~cm}$, or a rapid increase in the aortic diameter. Open surgery is still preferred as experience with intravascular stenting in MFS is very limited, 
and the pressure endovascular stents need to apply against the wall of adjacent normal sized aortic segments to remain well seated may not be tolerated by weakened connective tissue, or the adjacent aorta may also be dilated. Regular imaging of the entire aorta is encouraged after root surgery and in adulthood.

Mitral valve repair or replacement is advised for severe mitral valve regurgitation with associated symptoms or progressive left ventricular dilatation or dysfunction. Repair should be considered, especially in patients undergoing aortic valve sparing root replacement. If a mechanical aortic valve prosthesis is chosen, mitral valve replacement may be considered, although preservation of left ventricular function may be better with mitral valve repair. After isolated mitral valve repair, one should carefully monitor aortic root size as increased rates of enlargement have been observed.

Decisions regarding exercise restriction should always be made on an individual basis. Recommendations from the National Marfan Foundation (http://www.marfan.org) and guidelines from the American Heart Association/American College of Cardiology task forces ${ }^{73}$ are useful templates. In general, patients with MFS should avoid contact sports, exercise to exhaustion and especially isometric activities involving a Valsalva manoeuvre. Most patients can and should participate in aerobic activities performed in moderation.

Pregnancy in MFS women is associated with increased cardiovascular risk, with the majority of aortic complications (progressive dilatation and dissection) occurring in the third trimester or in the early postpartum period. The risk of aortic root complication is increased when the aortic root diameter is above $4.0 \mathrm{~cm}$ at the start of the pregnancy. ${ }^{74}$

Annual ophthalmological evaluation for the detection of ectopia lentis, cataract, glaucoma and retinal detachment is essential. Early monitoring and aggressive refraction is required for children with MFS to prevent amblyopia. Indications for surgical lens extraction include lens opacity with poor visual function, anisometropia or refractive error not amenable to optical correction, impending complete luxation, and lens induced glaucoma or uveitis.

Skeletal manifestations such as scoliosis and pectus deformity should be treated according to standard orthopaedic management rules.

\section{Management guidelines for related conditions}

Regular follow-up including annual cardiovascular imaging and ophthalmological evaluation is advised in MASS, MVPS and ELS to monitor aortic size, and the degree of mitral regurgitation, over time. Counselling for patients with either ELS or MASS phenotype should include the risk of a more severe presentation in their offspring, including aortic enlargement.

Careful cardiovascular and ophthalmological follow-up is strongly indicated in children with potential MFS or non-specific connective tissue disorders.

\section{CONCLUSION}

The diagnostic evaluation for MFS is unavoidably complex due to the highly variable presentation of affected individuals, the age dependent nature of many of its manifestations, the absence of gold standards, and its extensive differential diagnosis. While diagnostic criteria should emphasise simplicity of use and the desire for early diagnosis, accuracy receives highest priority in order to avoid the deleterious and often irreversible consequences of ungrounded or erroneous assignment. While the increased focus on vascular disease for the diagnosis of MFS in this proposal will likely prove controversial, it is responsive to the practical burden faced both by patients and physicians and does not represent a true departure from the spirit of prior diagnostic guidelines. Ongoing concerns about delayed diagnosis and/or the use of diagnostic categories that may prove provisional should be offset by additional discussion of ongoing risk and the definition of follow-up and management principles. A comparative analysis on different retrospective datasets has shown $\sim 90 \%$ concordance between the old and revised Ghent nosology. The $10 \%$ discordance was generally beneficial by facilitating earlier diagnosis in young children with a convincing clinical phenotype and delayed diagnosis in individuals without clear cardiovascular risk. The current proposal will benefit from a prospective analysis, leading to further refinement. A web based diagnostic tool for the application of these criteria can be accessed at http://www.marfan.org.

Acknowledgements The expert panel meeting took place in February 2007 with support of the National Marfan Foundation and consisted of Bart Loeys, Harry Dietz, Alan Braverman, Richard Devereux, Guillaume Jondeau, Laurence Faivre, Dianna Milewicz, Reed Pyeritz, Paul Sponseller, Paul Wordsworth and Anne De Paepe.

Competing interests None.

Provenance and peer review Not commissioned; externally peer reviewed.

\section{REFERENCES}

1. Marfan AB. Un cas de deformation congenitale des quatre membres plus prononcee aux extremites characterisee par l'allongment des os avec un certain degre d'amincissement. Bull Mem Soc Med Hop Paris 1896;13:220-1.

2. Mc Kusick VA. The cardiovascular aspects of Marfan's syndrome: a heritable disorder of connective tissue. Circulation 1955;11:321-42.

3. Mc Kusick VA. Heritable disorders of connective tissue. St Louis: C.V. Mosby Co. 1956.

4. Beighton P, de Paepe A, Danks D, Finidori G, Gedde-Dahl T, Goodman R, Hall JG, Hollister DW, Horton W, McKusick VA, et al. International Nosology of Heritable Disorders of Connective Tissue, Berlin, 1986. Am J Med Genet 1988;29:581-94.

5. Dietz HC, Cutting GR, Pyeritz RE, Maslen CL, Sakai LY, Corson GM, Puffenberger EG, Hamosh A, Nanthakumar EJ, Curristin SM, et al. Marfan syndrome caused by a recurrent de novo missense mutation in the fibrillin gene. Nature 1991;352 337-9.

6. De Paepe A, Devereux RB, Dietz HC, Hennekam RC, Pyeritz RE. Revised diagnostic criteria for the Marfan syndrome. Am J Med Genet 1996;62:417-26.

7. Loeys B, Nuytinck L, Delvaux I, De Bie S, De Paepe A. Genotype and phenotype analysis of 171 patients referred for molecular study of the fibrillin-1 gene FBN1 because of suspected Marfan syndrome. Arch Intern Med 2001;161:2447-54

8. Loeys B, De Backer J, Van Acker P, Wettinck K, Pals G, Nuytinck L, Coucke P, De Paepe A. Comprehensive molecular screening of the FBN1 gene favors locus homogeneity of classical Marfan syndrome. Hum Mutat 2004;24:140-6.

9. Faivre L, Masurel-Paulet A, Collod-Beroud G, Callewaert BL, Child AH, Stheneur C, Binquet C, Gautier E, Chevallier B, Huet F, Loeys BL, Arbustini E, Mayer K, Arslan-Kirchner M, Kiotsekoglou A, Comeglio P, Grasso M, Halliday DJ, Beroud C, Bonithon-Kopp C, Claustres M, Robinson PN, Ades L, De Backer J, Coucke P, Francke U, De Paepe A, Boileau C, Jondeau G. Clinical and molecular study of 320 children with Marfan syndrome and related type I fibrillinopathies in a series of 1009 probands with pathogenic FBN1 mutations. Pediatrics 2009;123:391-8.

10. Glesby MJ, Pyeritz RE. Association of mitral valve prolapse and systemic abnormalities of connective tissue. A phenotypic continuum. JAMA 1989;262:523-8.

11. Faivre L, Collod-Beroud G, Child A, Callewaert B, Loeys BL, Binquet C, Gautier E, Arbustini E, Mayer K, Arslan-Kirchner M, Stheneur C, Kiotsekoglou A, Comeglio P, Marziliano N, Halliday D, Beroud C, Bonithon-Kopp C, Claustres M, Plauchu H, Robinson PN, Ades L, De Backer J, Coucke P, Francke U, De Paepe A, Boileau C, Jondeau G. Contribution of molecular analyses in diagnosing Marfan syndrome and type I fibrillinopathies: an international study of 1009 probands. J Med Genet 2008; 45:384-90.

12. Faivre L, Collod-Beroud G, Loeys BL, Child A, Binquet C, Gautier E, Callewaert B, Arbustini E, Mayer K, Arslan-Kirchner M, Kiotsekoglou A, Comeglio P, Marziliano N, Dietz HC, Halliday D, Beroud C, Bonithon-Kopp C, Claustres M, Muti C, Plauchu H, Robinson PN, Ades LC, Biggin A, Benetts B, Brett M, Holman KJ, De Backer J, Coucke P, Francke U, De Paepe A, Jondeau G, Boileau C. Effect of mutation type and location on clinical outcome in 1,013 probands with Marfan syndrome or related phenotypes and FBN1 mutations: an international study. Am J Hum Genet 2007:81:454-66.

13. Roman MJ, Devereux RB, Kramer-Fox R, O'Loughlin J. Two-dimensional echocardiographic aortic root dimensions in normal children and adults. Am J Cardiol 1989;64:507-12. 
14. Lin FY, Devereux RB, Roman MJ, Meng J, Jow VM, Jacobs A, Weinsaft JW, Shaw LJ, Berman DS, Gilmore A, Callister TQ, Min JK. Assessment of the thoracic aorta by multidetector computed tomography: age- and sex-specific reference values in adults without evident cardiovascular disease. J Cardiovasc Comput Tomogr 2008;2:298-308.

15. Weissman NJ, Pini R, Roman MJ, Kramer-Fox R, Andersen HS, Devereux RB. In vivo mitral valve morphology and motion in mitral valve prolapse. Am J Cardiol 1994;73:1080-8.

16. De Backer J, Loeys B, Devos D, Dietz H, De Sutter J, De Paepe A. A critical analysis of minor cardiovascular criteria in the diagnostic evaluation of patients with Marfan syndrome. Genet Med 2006;8:401-8.

17. Bee KJ, Wilkes D, Devereux RB, Lerman BB, Dietz HC, Basson CT. Structural and functional genetic disorders of the great vessels and outflow tracts. Ann N Y Acad Sci 2006; 1085:256-69.

18. Rybczynski M, Bernhardt AM, Rehder U, Fuisting B, Meiss L, Voss U, Habermann C, Detter C, Robinson PN, Arslan-Kirchner M, Schmidtke J, Mir TS, Berger J, Meinertz T, von Kodolitsch Y. The spectrum of syndromes and manifestations in individuals screened for suspected Marfan syndrome. Am J Med Genet A 2008:146A:3157-66.

19. Lindsey JM, Michelson JD, MacWilliams BA, Sponseller PD, Miller NH. The foot in Marfan syndrome: clinical findings and weight-distribution patterns. J Pediatr Orthop 1998; 18:755-9.

20. Villeirs GM, Van Tongerloo AJ, Verstraete KL, Kunnen MF, De Paepe AM. Widening of the spinal canal and dural ectasia in Marfan's syndrome: assessment by CT. Neuroradiology 1999;41:850-4.

21. Ahn NU, Nallamshetty L, Ahn UM, Buchowski JM, Rose PS, Garrett ES, Kebaish KM, Sponseller PD. Dural ectasia and conventional radiography in the Marfan lumbosacral spine. Skeletal Radiol 2001;30:338-45.

22. Oosterhof T, Groenink M, Hulsmans FJ, Mulder BJ, van der Wall EE, Smit R, Hennekam RC. Quantitative assessment of dural ectasia as a marker for Marfan syndrome. Radiology 2001;220:514-18.

23. Weigang E, Ghanem N, Chang XC, Richter H, Frydrychowicz A, Szabo G, Dudeck O, Knirsch W, von Samson $P$, Langer M, Beyersdorf F. Evaluation of three different measurement methods for dural ectasia in Marfan syndrome. Clin Radiol 2006;61:971-8.

24. Sponseller PD, Jones KB, Ahn NU, Erkula G, Foran JR, Dietz HC 3rd. Protrusio acetabuli in Marfan syndrome: age-related prevalence and associated hip function. J Bone Joint Surg Am 2006;88:486-95.

25. Akutsu K, Morisaki H, Takeshita S, Ogino H, Higashi M, Okajima T, Yoshimuta T, Tsutsumi Y, Nonogi H, Morisaki T. Characteristics in phenotypic manifestations of genetically proved Marfan syndrome in a Japanese population. Am J Cardiol 2009;103:1146-8.

26. Reeves SL, Varakamin C, Henry CJ. The relationship between arm-span measurement and height with special reference to gender and ethnicity. Eur J Clin Nutr 1996;50:398-400.

27. Sponseller PD, Hobbs W, Riley LH 3rd, Pyeritz RE. The thoracolumbar spine in Marfan syndrome. J Bone Joint Surg Am 1995;71:867-76.

28. Dietz HC, Mclntosh I, Sakai LY, Corson GM, Chalberg SC, Pyeritz RE, Francomano CA. Four novel FBN1 mutations: significance for mutant transcript level and EGF-like domain calcium binding in the pathogenesis of Marfan syndrome. Genomics 1993:17:468-75

29. Devereux RB, Brown WT, Kramer-Fox R, Sachs I. Inheritance of mitral valve prolapse: effect of age and sex on gene expression. Ann Intern Med 1982:97:826-32.

30. Disse S, Abergel E, Berrebi A, Houot AM, Le Heuzey JY, Diebold B, Guize L, Carpentier $\mathrm{A}$, Corvol $\mathrm{P}$, Jeunemaitre $\mathrm{X}$. Mapping of a first locus for autosoma dominant myxomatous mitral-valve prolapse to chromosome 16p11.2-p12.1. Am J Hum Genet 1999;65:1242-51.

31. Kyndt F, Schott JJ, Trochu JN, Baranger F, Herbert O, Scott V, Fressinaud E, David A, Moisan JP, Bouhour JB, Le Marec H, Benichou B. Mapping of X-linked myxomatous valvular dystrophy to chromosome Xq28. Am J Hum Genet 1998;62:627-32.

32. Roman MJ, Devereux RB, Kramer-Fox R, Spitzer MC. Comparison of cardiovascular and skeletal features of primary mitral valve prolapse and Marfan syndrome. Am J Cardiol 1989;63:317-21.

33. Loeys BL, Chen J, Neptune ER, Judge DP, Podowski M, Holm T, Meyers J, Leitch CC, Katsanis N, Sharifi N, Xu FL, Myers LA, Spevak PJ, Cameron DE, De Backer J, Hellemans J, Chen Y, Davis EC, Webb CL, Kress W, Coucke P, Rifkin DB, De Paepe AM, Dietz HC. A syndrome of altered cardiovascular, craniofacial, neurocognitive and skeletal development caused by mutations in TGFBR1 or TGFBR2. Nat Genet 2005:37:275-81.

34. Loeys BL, Schwarze U, Holm T, Callewaert BL, Thomas GH, Pannu H, De Backer JF, Oswald GL, Symoens S, Manouvrier S, Roberts AE, Faravelli F, Greco MA, Pyeritz RE, Milewicz DM, Coucke PJ, Cameron DE, Braverman AC, Byers PH, De Paepe AM, Dietz HC. Aneurysm syndromes caused by mutations in the TGF-beta receptor. N Engl J Med 2006;355:788-98.

35. Mizuguchi T, Collod-Beroud G, Akiyama T, Abifadel M, Harada N, Morisaki T, Allard $D$, Varret M, Claustres M, Morisaki H, Ihara M, Kinoshita A, Yoshiura K, Junien C, Kajii T, Jondeau G, Ohta T, Kishino T, Furukawa Y, Nakamura Y, Nikawa N, Boileau C, Matsumoto N. Heterozygous TGFBR2 mutations in Marfan syndrome. Nat Genet 2004;36:855-60

36. Singh KK, Rommel K, Mishra A, Karck M, Haverich A, Schmidtke J, Arslan-Kirchner M. TGFBR1 and TGFBR2 mutations in patients with features of Marfan syndrome and Loeys-Dietz syndrome. Hum Mutat 2006;27:770-7.
37. Stheneur C, Collod-Beroud G, Faivre L, Gouya L, Sultan G, Le Parc JM, Moura B, Attias D, Muti C, Sznajder M, Claustres M, Junien C, Baumann C, Cormier-Daire V, Rio M, Lyonnet S, Plauchu H, Lacombe D, Chevallier B, Jondeau G, Boileau C. Identification of 23 TGFBR2 and 6 TGFBR1 gene mutations and genotype-phenotype investigations in 457 patients with Marfan syndrome type I and II, Loeys-Dietz syndrome and related disorders. Hum Mutat 2008:29:E284-95.

38. Movahed MR, Hepner AD, Ahmadi-Kashani M. Echocardiographic prevalence of bicuspid aortic valve in the population. Heart Lung Circ 2006;15:297-9.

39. Basso C, Boschello M. Perrone C, Mecenero A, Cera A, Bicego D, Thiene G, De Dominicis E. An echocardiographic survey of primary school children for bicuspid aortic valve. Am J Cardiol 2004;93:661-3.

40. Loscalzo ML, Goh DL, Loeys B, Kent KC, Spevak PJ, Dietz HC. Familial thoracic aortic dilation and bicommissural aortic valve: a prospective analysis of natural history and inheritance. Am J Med Genet A 2007;143A:1960-7.

41. Nkomo VT, Enriquez-Sarano M, Ammash NM, Melton LJ 3rd, Bailey KR, Desjardins V. Horn RA, Tajik AJ. Bicuspid aortic valve associated with aortic dilatation: a community-based study. Arterioscler Thromb Vasc Biol 2003:23:351-6.

42. Hahn RT, Roman MJ, Mogtader AH, Devereux RB. Association of aortic dilation with regurgitant, stenotic and functionally normal bicuspid aortic valves. J Am Coll Cardiol 1992;19:283-8.

43. Martin LJ, Ramachandran V, Cripe LH, Hinton RB, Andelfinger G, Tabangin M, Shooner K, Keddache M, Benson DW. Evidence in favor of linkage to human chromosomal regions 18q, 5q and 13q for bicuspid aortic valve and associated cardiovascular malformations. Hum Genet 2007;121:275-84.

44. Vaughan CJ, Casey M, He J, Veugelers M, Henderson K, Guo D, Campagna R, Roman MJ, Milewicz DM, Devereux RB, Basson CT. Identification of a chromosome 11q23.2-q24 locus for familial aortic aneurysm disease, a genetically heterogeneous disorder. Circulation 2001:103:2469-75.

45. Guo D, Hasham S, Kuang SQ, Vaughan CJ, Boerwinkle E, Chen H, Abuelo D, Dietz HC, Basson CT, Shete SS, Milewicz DM. Familial thoracic aortic aneurysms and dissections: genetic heterogeneity with a major locus mapping to 5q13-14. Circulation 2001;103:2461-8.

46. Zhu L, Vranckx R, Khau Van Kien P, Lalande A, Boisset N, Mathieu F, Wegman M, Glancy L, Gasc JM, Brunotte F, Bruneval P. Wolf JE, Michel JB, Jeunemaitre X. Mutations in myosin heavy chain 11 cause a syndrome associating thoracic aortic aneurysm/aortic dissection and patent ductus arteriosus. Nat Genet 2006:38:343-9.

47. Guo DC, Pannu H, Tran-Fadulu V, Papke CL, Yu RK, Avidan N, Bourgeois S, Estrera AL, Safi HJ, Sparks E, Amor D, Ades L, McConnell V, Willoughby CE, Abuelo D, Willing M, Lewis RA, Kim DH, Scherer S, Tung PP, Ahn C, Buja LM, Raman CS, Shete SS, Milewicz DM. Mutations in smooth muscle alpha-actin (ACTA2) lead to thoracic aortic aneurysms and dissections. Nat Genet 2007:39:1488-93.

48. Guo DC, Papke CL, Tran-Fadulu V, Regalado ES, Avidan N, Johnson RJ, Kim DH, Pannu H, Willing MC, Sparks E, Pyeritz RE, Singh MN, Dalman RL, Grotta JC, Marian AJ, Boerwinkle EA, Frazier LQ, LeMaire SA, Coselli JS, Estrera AL, Safi HJ, Veeraraghavan S, Muzny DM, Wheeler DA, Willerson JT, Yu RK, Shete SS, Schere SE, Raman CS, Buja LM, Milewicz DM. Mutations in smooth muscle alpha-actin (ACTA2) cause coronary artery disease, stroke, and moyamoya disease, along with thoracic aortic disease. Am J Hum Genet 2009;84:617-27.

49. Pepin M, Schwarze U, Superti-Furga A, Byers PH. Clinical and genetic features of Ehlers-Danlos syndrome type IV, the vascular type. N Engl J Med 2000;342:673-80.

50. Wenstrup RJ, Murad S, Pinnell SR. Ehlers-Danlos syndrome type VI: clinical manifestations of collagen lysyl hydroxylase deficiency. J Pediatr 1989;115:405-9.

51. Schwarze U, Hata R, McKusick VA, Shinkai H, Hoyme HE, Pyeritz RE, Byers PH. Rare autosomal recessive cardiac valvular form of Ehlers-Danlos syndrome results from mutations in the COL1A2 gene that activate the nonsense-mediated RNA decay pathway. Am J Hum Genet 2004;74:917-30.

52. Malfait F, Symoens S, De Backer J, Hermanns-Le T, Sakalihasan N, Lapiere CM, Coucke P, De Paepe A. Three arginine to cysteine substitutions in the pro-alpha (I)collagen chain cause Ehlers-Danlos syndrome with a propensity to arterial rupture in early adulthood. Hum Mutat 2007;28:387-95.

53. Wessels MW, Catsman-Berrevoets CE, Mancini GM, Breuning MH, Hoogeboom JJ Stroink H, Frohn-Mulder I, Coucke PJ, Paepe AD, Niermeijer MF, Willems PJ. Three new families with arterial tortuosity syndrome. Am J Med Genet $A$ 2004;131:134-43.

54. Coucke PJ, Willaert A, Wessels MW, Callewaert B, Zoppi N, De Backer J, Fox JE, Mancini GM, Kambouris M, Gardella R, Facchetti F, Willems PJ, Forsyth R, Dietz HC, Barlati S, Colombi M, Loeys B, De Paepe A. Mutations in the facilitative glucose transporter GLUT10 alter angiogenesis and cause arterial tortuosity syndrome. Nat Genet 2006;38:452-7.

55. Callewaert BL, Willaert A, Kerstjens-Frederikse WS, De Backer J, Devriendt K, Albrecht B, Ramos-Arroyo MA, Doco-Fenzy M, Hennekam RC, Pyeritz RE, Krogmann ON, Gillessen-kaesbach G, Wakeling EL, Nik-zainal S, Francannet C, Mauran P, Booth C, Barrow M, Dekens R, Loeys BL, Coucke PJ, De Paepe AM. Arterial tortuosity syndrome: clinical and molecular findings in 12 newly identified families. Hum Mutat 2008;29:150-8.

56. Ades LC, Holman KJ, Brett MS, Edwards MJ, Bennetts B. Ectopia lentis phenotypes and the FBN1 gene. Am J Med Genet A 2004;126A:284-9.

57. Desir J, Snzajer Y, Depasse F, Roulez F, Schrooyen M, Meire F, Abramowicz M. LTBP2 mutations in autosomal recessive syndrome with megalocornia, spherophakia and secondary glaucoma. Eur J Hum Genet 2010;18:761-7. 
58. Ahram D, Sato TS, Kohilan A, Tayeh M, Chen S, Leal S, Al-Salem M, El-Shanti H. A homozygous mutation in ADAMTSL4 causes autosomal-recessive isolated ectopia lentis. Am J Hum Genet 2009;84:274-8.

59. Faivre L, Dollfus H, Lyonnet S, Alembik Y, Megarbane A, Samples J, Gorlin RJ, Alswaid A, Feingold J, Le Merrer M, Munnich A, Cormier-Daire V. Clinical homogeneity and genetic heterogeneity in Weill-Marchesani syndrome. Am J Med Genet A 2003;123A:204-7.

60. Faivre L, Gorlin RJ, Wirtz MK, Godfrey M, Dagoneau N, Samples JR, Le Merrer M, Collod-Beroud G, Boileau C, Munnich A, Cormier-Daire V. In frame fibrillin-1 gene deletion in autosomal dominant Weill-Marchesani syndrome. J Med Genet 2003;40:34-6.

61. Dagoneau N, Benoist-Lasselin C, Huber C, Faivre L, Megarbane A, Alswaid A, Dollfus H, Alembik Y, Munnich A, Legeai-Mallet L, Cormier-Daire V. ADAMTS10 mutations in autosomal recessive Weill-Marchesani syndrome. Am J Hum Genet 2004; 75:801-6.

62. Sood S, Eldadah ZA, Krause WL, McIntosh I, Dietz HC. Mutation in fibrillin-1 and the Marfanoid-craniosynostosis (Shprintzen-Goldberg) syndrome. Nat Genet 1996;12:209-11.

63. Kosaki K, Takahashi D, Udaka T, Kosaki R, Matsumoto M, Ibe S, Isobe T, Tanaka Y, Takahashi T. Molecular pathology of Shprintzen-Goldberg syndrome. Am J Med Genet A 2006;140:104-8. [author reply 109-10].

64. Robinson PN, Neumann LM, Tinschert S. Response to Kosaki et al "Molecular pathology of Shprintzen-Goldberg syndrome". Am J Med Genet 2006;140A 109-10.

65. Callewaert BL, Loeys BL, Ficcadenti A, Vermeer S, Landgren M, Kroes HY, Yaron Y, Pope M, Foulds N, Boute O, Galan F, Kingston H, Van der Aa N, Salcedo I, Swinkels ME, Wallgren-Pettersson C, Gabrielli 0, De Backer J, Coucke PJ, De Paepe AM. Comprehensive clinical and molecular assessment of 32 probands with congenital contractural arachnodactyly: report of 14 novel mutations and review of the literature. Hum Mutat 2009;30:334-41.

66. Gupta PA, Putnam EA, Carmical SG, Kaitila I, Steinmann B, Child A, Danesino C, Metcalfe K, Berry SA, Chen E, Delorme CV, Thong MK, Ades LC, Milewicz DM. Ten novel FBN2 mutations in congenital contractural arachnodactyly: delineation of the molecular pathogenesis and clinical phenotype. Hum Mutat 2002;19:39-48.

67. Putnam EA, Zhang H, Ramirez F, Milewicz DM. Fibrillin-2 (FBN2) mutations result in the Marfan-like disorder, congenital contractural arachnodactyly. Nat Genet 1995;11:456-8.

68. Shores J, Berger KR, Murphy EA, Pyeritz RE. Progression of aortic dilatation and the benefit of long-term beta-adrenergic blockade in Marfan's syndrome. N Engl J Med 1994;330:1335-41.

69. Ahimastos AA, Aggarwal A, D'Orsa KM, Formosa MF, White AJ, Savarirayan R, Dart AM, Kingwell BA. Effect of perindopril on large artery stiffness and aortic roo diameter in patients with Marfan syndrome: a randomized controlled trial. JAMA 2007:298:1539-47.

70. Habashi JP, Judge DP, Holm TM, Cohn RD, Loeys BL, Cooper TK, Myers L, Klein EC Liu G, Calvi C, Podowski M, Neptune ER, Halushka MK, Bedja D, Gabrielson K, Rifkin DB, Carta L, Ramirez F, Huso DL, Dietz HC. Losartan, an AT1 antagonist, prevents aortic aneurysm in a mouse model of Marfan syndrome. Science 2006;312:117-21

71. Brooke BS, Habashi JP, Judge DP, Patel N, Loeys B, Dietz HC 3rd. Angiotensin II blockade and aortic-root dilation in Marfan's syndrome. N Engl J Med 2008; 358:2787-95.

72. Lacro RV, Dietz HC, Wruck LM, Bradley TJ, Colan SD, Devereux RB, Klein GL, Li JS Minich LL, Paridon SM, Pearson GD, Printz BF, Pyeritz RE, Radojewski E, Roman MJ Saul JP, Stylianou MP, Mahony L. Rationale and design of a randomized clinical trial of beta-blocker therapy (atenolol) versus angiotensin II receptor blocker therapy (losartan) in individuals with Marfan syndrome. Am Heart J 2007;154:624-31.

73. Maron BJ, Chaitman BR, Ackerman MJ, Bayes de Luna A, Corrado D, Crosson JE, Deal BJ, Driscoll DJ, Estes NA 3rd, Araujo CG, Liang DH, Mitten MJ, Myerburg RJ Pelliccia A, Thompson PD, Towbin JA, Van Camp SP. Recommendations for physical activity and recreational sports participation for young patients with genetic cardiovascular diseases. Circulation 2004;109:2807-16.

74. Rossiter JP, Repke JT, Morales AJ, Murphy EA, Pyeritz RE. A prospective longitudinal evaluation of pregnancy in the Marfan syndrome. Am J Obstet Gynecol 1995:173:1599-606

\section{Correction}

L Guillot, R Epaud, G Thouvenin, L Jonard, A Mohsni, R Couderc, F Counil, J de Blic, R A Taam, M Le Bourgeois, P Reix, F Flamein, A Clement, D Feldmann. New surfactant protein C gene mutations associated with diffuse lung disease (J Med Genet 2009;46:490-4). There is an error in the genetic family tree of the L194P mutation. The authors would like to point out that it is the father who harbours and transmits the mutation to his child (arrow) and not the mother as published. The corrected figure is published below.
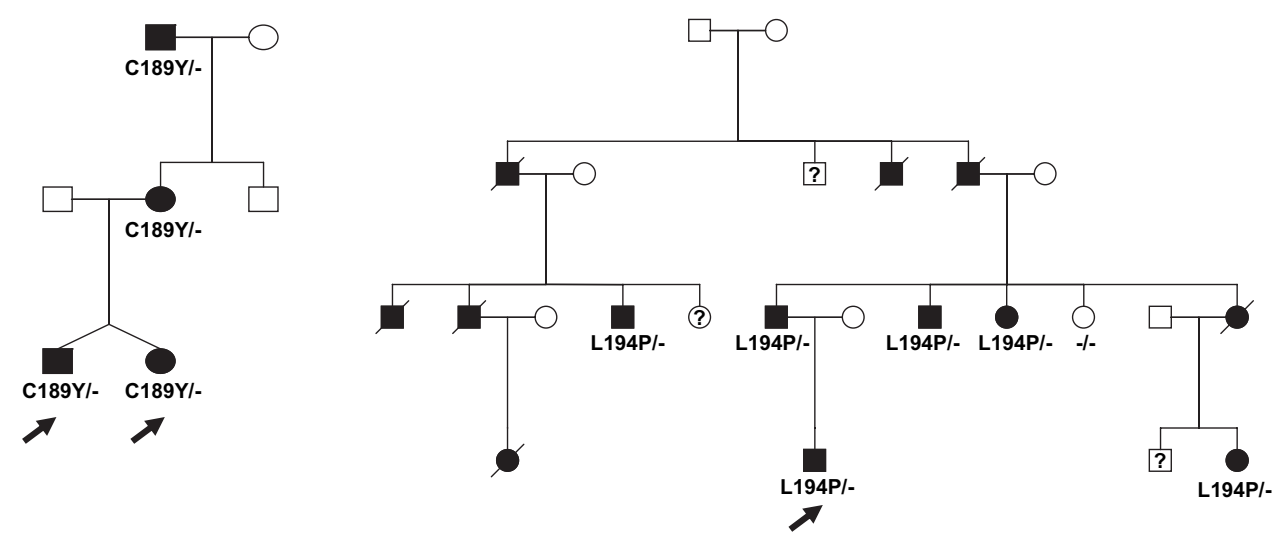

J Med Genet 2010:47:485. doi:10.1136/jmg.2009.066829corr1 